\title{
Site fidelity of escaped rainbow trout to an experimental freshwater aquaculture facility and habitat overlap with native fish fauna
}

\author{
Colin Charles ${ }^{1,2, *}$, Paul J. Blanchfield ${ }^{1,2}$, Darren M. Gillis ${ }^{1}$ \\ ${ }^{1}$ Department of Biological Sciences, University of Manitoba, Winnipeg, Manitoba R3T 2N2, Canada \\ ${ }^{2}$ Freshwater Institute, Fisheries and Oceans Canada, Winnipeg, Manitoba R3T 2N6, Canada
}

\begin{abstract}
The distribution and habitat use of escaped farmed fish is often difficult to assess after their dispersal from commercial open-pen aquaculture facilities. We examined site fidelity of rainbow trout Oncorhynchus mykiss after release from an experimental farm (escaped fish) in a small lake, as well as habitat overlap (3D kernel utilization distributions) with a native salmonid, lake trout Salvelinus namaycush. Fish were implanted with telemetry transmitters, and their movements were monitored by acoustic arrays during (2006-2007) and after (2008-2009) commercial production. This latter period allowed for assessment of habitat use by escapees in the absence of any influence of cage production, simulating conditions similar to fallowing or longdistance dispersal. Escaped rainbow trout were regularly present at the cage site $(23 \%$ of total positions) during production, typically at times of the day which coincided with feeding, but were rarely near the cage site ( $2 \%$ of total positions) during the post-production period, and instead greatly increased their occupancy of the near-shore region. Lake trout did not display an affinity to the cage site in either the production or post-production periods $(\sim 1 \%$ of total positions), and volumetric overlap with rainbow trout was relatively low throughout the entire study. Our results indicate that in the absence of ongoing production at commercial aquaculture operations, rainbow trout escapees can readily switch to foraging on native fauna in the near-shore regions of the lake and did not directly compete with native lake trout.
\end{abstract}

KEY WORDS: 3D kernel utilization distribution - Escapees - Habitat overlap - Lake trout · Salvelinus namaycush $\cdot$ Oncorhynchus mykiss $\cdot$ Salmonid $\cdot$ Dispersal

\section{INTRODUCTION}

The growing global demand for fish has led to the rapid growth of intensive aquaculture practices (FAO 2016). The fate of escaped farmed fish from marineor freshwater-based net pens, especially salmonids, is among the key environmental concerns associated with this type of commercial aquaculture production worldwide (Naylor et al. 2005, Soto et al. 2006), and presents serious challenges for aquaculture operators, law makers and the public (Pascual et al. 2009).

\footnotetext{
*Corresponding author: colin.charles@hotmail.com
}

Escaped farm salmonids have the ability to negatively affect wild fish populations through high propagule pressure, competition and interbreeding (Gross 1998, Naylor et al. 2005, Consuegra et al. 2011). After an escape event, farmed salmonids disperse away from cage sites, and thus must begin to forage in their new environment to survive (Abrantes et al. 2011), leading to possible food-web disruptions and the potential to interact with native fish or wild conspecifics. Despite the potential negative ecological impacts of escaped farmed fish on aquatic ecosys-

(c) Fisheries and Oceans Canada and D. M. Gillis 2017. Open Access under Creative Commons by Attribution Licence. Use, distribution and reproduction are unrestricted. Authors and original publication must be credited.

Publisher: Inter-Research · www.int-res.com 
tems, it is often difficult to monitor their movements and habitat use under natural conditions because much of the world's salmonid aquaculture occurs in coastal areas of marine and fresh waters where current fish tracking technologies cannot provide highdetail movement data over large spatial scales (10s-100s km).

In Canada, commercial freshwater aquaculture of rainbow trout Oncorhynchus mykiss is a multimillion dollar industry. Although much smaller in scale than its marine counterpart, open-pen aquaculture production in fresh waters has grown by $>50 \%$ over the last decade (DFO 2015). Much of the commercial production of rainbow trout in Canada occurs in net pens located around the Manitoulin Island area of Lake Huron (Reid et al. 2006, Patterson \& Blanchfield 2013), from which farmed fish periodically escape (Johnston \& Wilson 2015). Escaped rainbow trout can remain in close proximity to commercial operations, as well as disperse widely into Lake Huron and adjoining Laurentian Great Lakes, and thus have the opportunity to interact with native fish species or with wild (naturalized) rainbow trout (Patterson \& Blanchfield 2013). Lake trout Salvelinus namaycush constitute an important component of the native Lake Huron fish community, and it is not known whether there is potential for habitat overlap with escaped farmed fish. While it is generally thought that these 2 species would be segregated by depth for much of the summer because of differences in thermal preference for optimal growth (lake trout: $10-12^{\circ} \mathrm{C}, \mathrm{O}^{\prime} \mathrm{Connor}$ et al. 1981 ; rainbow trout: $13.1^{\circ} \mathrm{C}$, Bear et al. 2007), there is potential for habitat overlap when surface waters are cool in the spring, and when lake trout move onshore to spawn in the fall. Further, because escaped rainbow trout show site fidelity to aquaculture operations (Blanchfield et al. 2009a, Patterson \& Blanchfield 2013), and because lake trout and other species are known to be present at cage sites in the wild (Johnston et al. 2010), commercial farms represent a nexus for inter-specific habitat overlap and interactions.

The environmental impacts of freshwater aquaculture, such as the release of solid and dissolved wastes or large-scale escapes of farmed fish, are still not fully established (Yan 2005, Podemski \& Blanchfield 2006). Large aquatic systems, where much of the world's aquaculture takes place, are also influenced by numerous other factors, such as surrounding landuse practices, non-point source pollution and species invasions, among others, that limit our ability to assess the potential impacts of commercial aquaculture and escaped farmed fish. This is the case for Lake Huron, which is undergoing significant changes to food-web structure and fish community composition (e.g. Riley et al. 2008, Dunlop et al. 2010). Furthermore, telemetry, which has proven a useful tool to monitor the movements and habitat use of aquatic animals, has limitations in the case of farmed salmonids that disperse long distances from cage sites. For example, many of the telemetered rainbow trout released from commercial farms in Lake Huron to simulate escape events rapidly dispersed away from the farms and were not detected again (Patterson \& Blanchfield 2013), a pattern also observed in studies of escapees in the marine environment (e.g. Chittenden et al. 2011). To overcome challenges related to understanding environmental impacts of freshwater aquaculture, we ran a modelscale commercial facility that raised $10 \mathrm{t}$ of rainbow trout annually in a pristine, experimental lake (Bristow et al. 2008, Findlay et al. 2009, Kullman et al. 2009, Paterson et al. 2010, 2011, Azevedo et al. 2011, Wellman et al. 2017). The small size of the lake allowed us to examine in detail the fate of escaped rainbow trout (Blanchfield et al. 2009a).

Each year of the model farm study, small numbers of farmed rainbow trout were released into the lake (to simulate escape events), and their movements monitored. Initial findings from the first few years of production showed low survival and high site fidelity of escaped farmed fish (Blanchfield et al. 2009a). Here we examine data from the latter years of the study, during (2006-2007, 'production') and after (2008-2009, 'post-production') the final years of commercial production, to identify the relative importance of farm operation on escapee behaviour. The post-production period could also be considered representative of escapee dispersal from cage sites in much larger aquatic systems because there was no influence of farm operation. The post-production period is also akin to fallowing, a common practice in salmonid aquaculture whereby production is temporarily ceased to allow for recovery of sediments and associated macrofauna, or to control for disease outbreak (McGhie et al. 2000, Zhulay et al. 2015, Ellis et al. 2016). A second objective of this study was to quantify inter- and intra-specific (rainbow trout and lake trout) differences in attraction to the aquaculture cage, and habitat overlap. We examined potential competition between native and farmed fish using 3-dimensional (3D) analysis methods to more accurately estimate interspecific habitat overlap by accounting for differences in depth distribution (Simpfendorfer et al. 2012). 


\section{MATERIALS AND METHODS}

\section{Study area and model farm}

All field work was conducted at the Experimental Lakes Area (ELA), located in northwestern Ontario. The ELA consists of 58 small glacial relict lakes whose watersheds are set aside for research purposes (Blanchfield et al. 2009b). We ran a small-scale commercial aquaculture operation ( 10 $\mathrm{t}$ annual production) in an experimental lake for 5 consecutive years (2003-2007). The study site, Lake 375 (93.787978 W, $\left.49.744958^{\circ} \mathrm{N}\right)$, is a small (23 ha) double-basin lake with maximum depths of 17 and $26 \mathrm{~m}$ in the north and south basins, respectively (Fig. 1). In the spring of
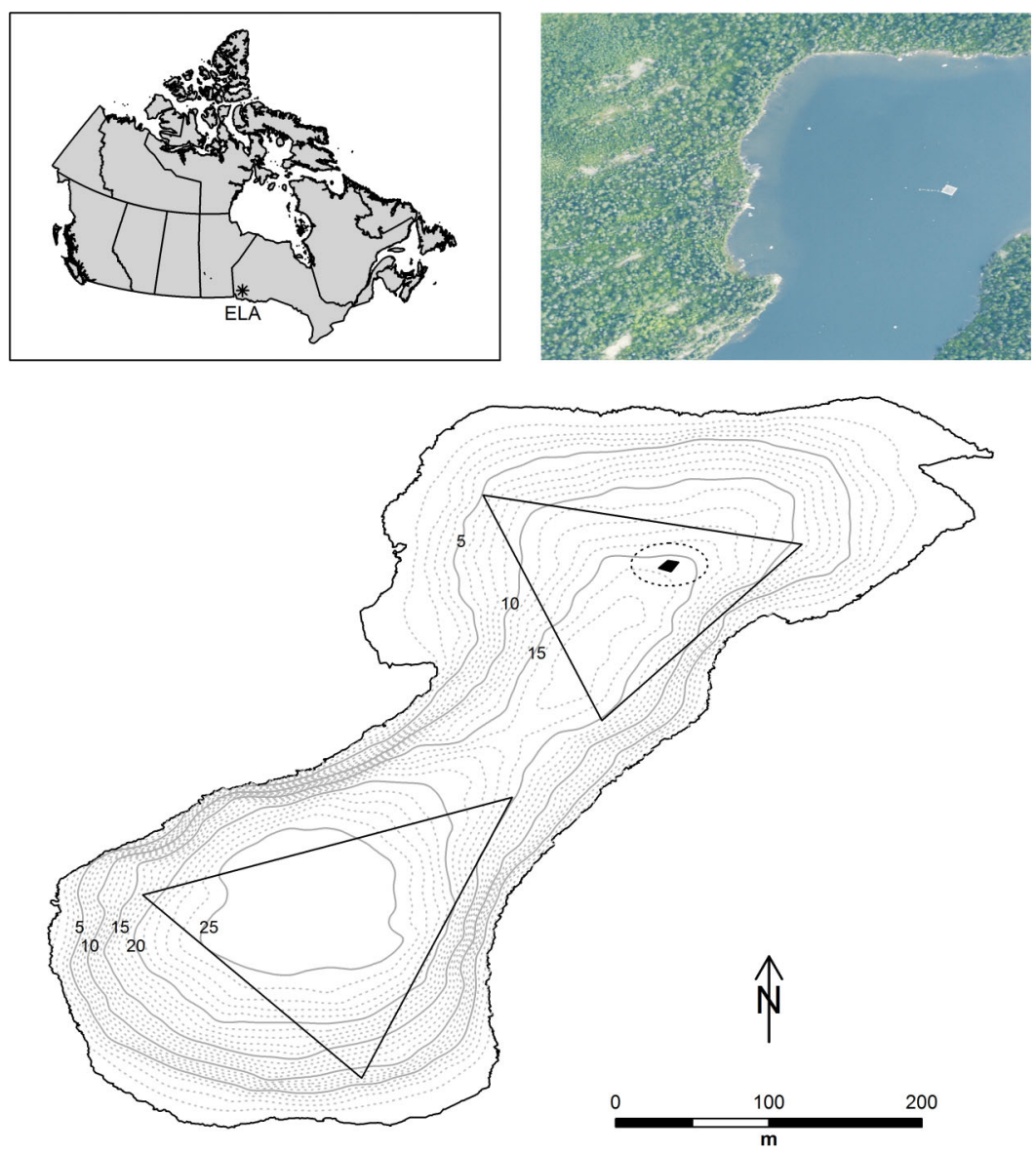

Fig. 1. Location of the Experimental Lakes Area (ELA) in northwestern Ontario, Canada (inset top left), where a model aquaculture facility that annually produced 10 t of rainbow trout Oncorhynchus mykiss from 2003-2007 was in operation in the north basin of Lake 375 (aerial photo, top right). Bathymetric map of Lake 375 with solid grey lines that represent $5 \mathrm{~m}$ depth contours in each basin are shown. We considered all fish positions inside the $5 \mathrm{~m}$ isopleth as 'littoral' and those at isopleths $>5 \mathrm{~m}$ as 'pelagic'. The locations of the hydrophones for each of the 2 telemetry systems are represented by the points of the triangles in the north and south basins. The cage (solid black square) with $25 \mathrm{~m}$ radius buffer (dashed black line) is also shown
2003, a large steel frame with boardwalk was installed in the north basin, over $15 \mathrm{~m}$ depth water, from which we suspended a commercial net pen measuring above the lake bottom. Roughly 10000 female rainbow trout fingerlings were transferred to the net each spring for a stocking biomass of $\sim 1000 \mathrm{~kg}$. Rainbow trout were manually fed twice daily, in the morning and evening, usually $2 \mathrm{~h}$ after sunrise and $2 \mathrm{~h}$ before sunset (Blanchfield et al. 2009a, Rooney \& Podemski 2009). Fish were harvested in October or November ( 5.5 mo later) at almost 10 times their initial weight ( 1 kg; annual average ranged from 808 to $1109 \mathrm{~g})$.

In addition to the $5 \mathrm{yr}$ of fish farm operation (2003-2007), we conducted 2 yr of background research prior to cage production (20012002), and 2 yr of ecosystem recovery observations (2008-2009). Lake 375 is a dimictic lake, but lack of complete turnover in the spring and autumn in the later years of farm operation, in addition to enhanced lake productivity, resulted in greater than normal hypolimnetic oxygen depletion in 2007 and 2008. The presence of cold, well-oxygenated water is needed to sustain populations of lake trout and Mysis diluviana (previously M. relicta) (Plumb \& Blanchfield 2009, Paterson et al. 2010, 2011). Therefore, bubblers were added to Lake 375 during spring turnover (5-11 May 2009) to temporarily increase gas exchange with deeper anoxic waters.

The native fish community in Lake 375 contains lake trout, white sucker Catostomus commersoni, slimy sculpin Cottus cognatus and numerous cyprinid species that are associated with the littoral region of the lake (fathead minnow Pimephales promelas, pearl dace Margariscus margarita, finescale dace Phoxinus neogaeus and northern redbelly dace Phoxinus eos; Sellers et al. 1998, Guzzo et al. 2014). Lake 375 does not have a pelagic prey fish species but does contain the freshwater shrimp Mysis, which is an important prey for many lake trout populations (Vander Zanden \& Rasmussen 1996). Mysis abundance declined throughout this study, almost to the point of disappearance (Paterson et al. 2011). 


\section{Fish tagging and telemetry array}

Each fall during cage production, rainbow trout were surgically implanted with pressure-sensing acoustic transmitters and released into Lake 375 to simulate an escape scenario (see Blanchfield et al. 2009a). Lake trout were tagged in the spring of each year, starting in 2002, and tagging continued annually throughout the study. The surgical tagging procedure is described in more detail elsewhere (Blanchfield et al. 2005, 2009a, Plumb \& Blanchfield 2009). Over the study period, fish were implanted with 2 different models of depth-sensing acoustic transmitters (V16P-4L prior to 2005, and V13P-1L thereafter; Vemco). For this study (2006-2009), only V13 transmitters (6 $\mathrm{g}$ in water, $33 \mathrm{~mm}$ length), which randomly transmitted a coded signal ('ping') every 120-300 s, were active. Acoustic transmitters in the fish were detected by 2 radio-acoustic positioning and telemetry (RAPT) systems located in the north and south basins of Lake 375 (Fig. 1). The RAPT systems consist of a triad of moored buoys, which house an omni-directional hydrophone that receives information from the implanted transmitters (transmitter ID, time of detection, and depth). Each triad of buoys transmits this information to an on-shore base station that calculates a spatial position (latitude and longitude) for each fish detection (additional details provided by Blanchfield et al. 2005). On average, the telemetry systems positioned fish every $1317 \mathrm{~s}$ (median $=696 \mathrm{~s}$ ) for rainbow trout and $894 \mathrm{~s}$ (median $=591 \mathrm{~s}$ ) for lake trout. Thus, we were able to simultaneously monitor the spatial and pelagic position (latitude, longitude, depth) of tagged rainbow trout and lake trout throughout much of the lake during the open-water season (May to November) for the 4 yr of this study.

\section{Dataset and manipulations}

Only fish positions that met the highest detection criteria of the RAPT software were included in our analyses. The RAPT system generally has more accurate and precise performance when tags are located within the triad of buoys, but less so when tags are located farther from the center of the buoy triads (Blanchfield et al. 2005, Charles et al. 2016). The accuracy of telemetry data from Lake 375 displayed significant bias across the spatial gradient of the lake, which we corrected using an ordinary kriging approach (Charles et al. 2016). To capture the seasonality of fish behaviour, we only included fish whose position was estimated at least 10 times $\mathrm{mo}^{-1}$ during the open-water season (May-October) of each year of study, so fish tagged in the fall of a given year were excluded from analysis for that year. Fish implanted with acoustic transmitters and the transmitters themselves are subject to many external factors once the fish are released back into the system (signal interference, tag failures, mortality, etc.). This natural and systematic variability resulted in the numbers of fish included in the analyses to vary among years (rainbow trout: $\mathrm{n}=9-10$, lake trout: $\mathrm{n}=$ 11-12; Table 1). All data manipulations and subsequent analyses were done using the $\mathrm{R}$ statistical programming language (R Core Team 2016).

\section{Temperature and oxygen measurements}

As part of the long-term monitoring program at the ELA, temperature and dissolved oxygen (DO) measurements during the open-water season were taken at $2 \mathrm{wk}$ intervals at $1 \mathrm{~m}$ depth intervals over the deepest part of the lake using a portable temperature and DO meter (YSI). In the metalimnion, where temperature change was $>1^{\circ} \mathrm{C} \mathrm{m}^{-1}$, the sampling interval was every $0.25 \mathrm{~m}$. Due to physiological constraints imposed by environmental variables upon lake trout during the stratified period, temperature $\left(<15^{\circ} \mathrm{C}\right)$ and DO $\left(>4 \mathrm{mg} \mathrm{l}^{-1}\right)$ measurements can be used to define habitat requirements (Plumb $\&$ Blanchfield 2009). Temperature and oxygen profiles were interpolated at $0.1 \mathrm{~m}$ intervals from the surface to the bottom of the lake for each profile. The optimum habitat for lake trout was defined for each profile as the depth in the water column that most closely corresponded to the temperature and DO constraints. Once these values were calculated for profile days, we used linear interpolation to estimate oxy-thermal habitat throughout the open-water seasons at $0.1 \mathrm{~m}$ depth increments, as well as to fill in any missing data.

\section{Kernel density estimator}

A common approach to measure space use is to calculate a kernel utilization distribution (KUD), which gives the probability density that an individual is found at a certain point in space (Worton 1987). Previously it was common for kernel densities to be estimated in 2 dimensions (2D, i.e. areal); however, areal estimates of species distribution may greatly overestimate habitat overlap if the species in 


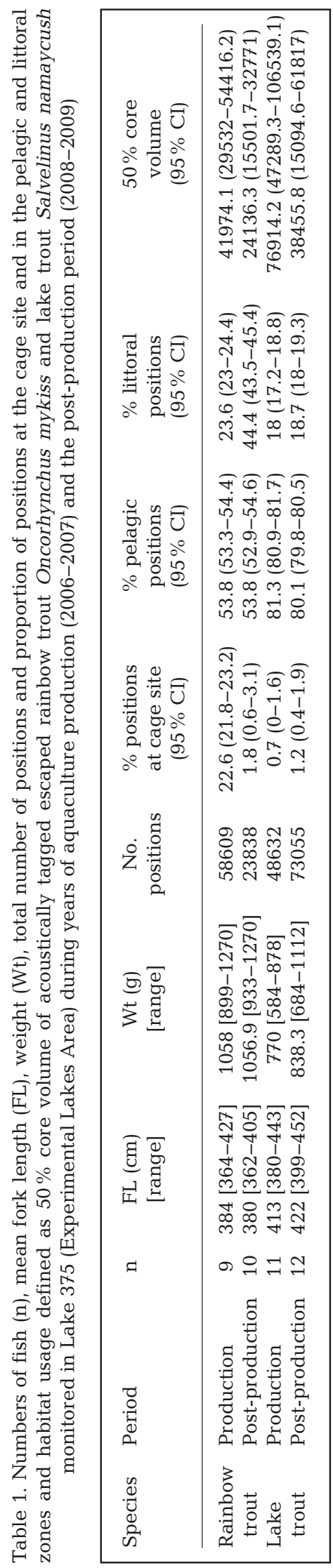

question occupy different depths (Simpfendorfer et al. 2012, Guzzo et al. 2016). To this end, we calculated 3D KUDs for individual fish (for examples, see the Supplement at www.int-res.com/articles/suppl/ q009p415_supp.txt), using the 'ks' package in $R$, which is able to analyse data from 1 to 6 dimensions (Duong 2007, 2016). We first converted fish spatial data from latitude and longitude to Universal Transverse Mercator (UTM), so that both the spatial and pelagic (depth) data were in the same units (m) from which we could estimate volumetric habitat use.

\section{Habitat use-overlap with cage site}

Fish presence around the cage site was measured in 2D and 3D. To measure space use around the cage in $2 \mathrm{D}$, a circular buffer with radius $25 \mathrm{~m}$ was defined from the center of the cage site (Fig. 1, dashed lined within north triad). The number of positions within the buffer was calculated for each individually tagged fish over the course of each day; the positions were binned into minutes for each day and smoothed lines were estimated using a generalized additive model in the geom_smooth() function of ggplot2. Secondly, a 3D near cage habitat $(\mathrm{NCH})$ was created by simulating a cylinder of $25 \mathrm{~m}$ radius from the lake surface to the bottom (see code in the Supplement). The cylinder was extended to the bottom of the lake because excess food not consumed by the farmed fish would settle to the sediments underneath the cage site (Rooney \& Podemski 2009). The NCH was used to calculate volumetric overlap of tagged fish with the cage site and represented $1.06 \%$ of the total lake volume.

\section{Habitat use - littoral, pelagic and cage site}

Fish habitat use was defined by the proportion of positions in the near-shore (littoral) and off-shore (pelagic) zones of Lake 375, and at the cage site during the periods of production and post-production. The littoral and pelagic zones were divided along the $5 \mathrm{~m}$ isopleth (outermost solid grey line in Fig. 1); any fish positions bounded by the $5 \mathrm{~m}$ isopleth and the shoreline were considered littoral, and those located off-shore from the $5 \mathrm{~m}$ isopleth were considered pelagic. The cage site was located within the pelagic zone, but we classified the cage site and pelagic zone separately. Any position within $25 \mathrm{~m}$ of the cage center was classified as presence at the cage site and 
removed from the estimate of pelagic habitat occupancy. We calculated the proportion of positions in each habitat type for each species and period of production. The littoral and pelagic zones accounted for 4.65 and $94.29 \%$ of the total lake volume, respectively.

\section{Habitat use - species overlap}

The volumes of the $50 \%$ KUDs were calculated using the 'ks' package in the R statistical environment (R Core Team 2016). We used the $50 \%$ KUDs to identify areas of high importance to tagged fish rather than $95 \%$ home range. To measure potential interaction between the species, we first determined 3D KUD intra-specific overlap for rainbow trout and lake trout, which allowed for comparison of the magnitude of inter-specific overlap (rainbow trout vs. lake trout). The 3D KUDs were calculated for each fish during the production and postproduction periods, and the overlap was calculated for each pair of fish in the dataset (see Table 1). The mean volumetric overlap (50\% KUD) and $95 \%$ confidence intervals (CI) were calculated for fish during the production and post-production periods.

\section{Statistical analysis}

We used a randomization test procedure to statistically compare cage overlap by each species. First, we compared the difference $\left(D_{1}\right)$ in means for each group, then randomly allocated samples to each group and recalculated the differences between the means $\left(D_{2}\right)$. We repeated the random allocation and recalculation 10000 times to generate a randomization distribution. Finally a p-value was calculated from the randomization samples, and the number of times the p-value exceed the value from the original groups was used to test whether the difference could have arisen from a random process under the null hypothesis of no difference (Manly 1997, see the Supplement for code).

The $95 \%$ confidence intervals for proportions were calculated as follows:

$$
p \pm 1.96 \times \sqrt{\frac{p(1-p)}{n}}
$$

where $p$ represents the sample proportion and is constrained between 0 and 1 , and $n$ represents the sample size of the population.

\section{RESULTS \\ Habitat use - overlap with cage site}

Based on their regular presence in close proximity to the cage site $(\leq 25 \mathrm{~m})$, escaped rainbow trout showed a clear attraction to the cage in production years (mean number of positions $\mathrm{d}^{-1} \pm 95 \%$ CI: 2006 : $3.66 \pm 0.12 ; 2007$ : $5.50 \pm 0.17$; Fig. 2). Moreover, daily timing of rainbow trout presence at the cage site occurred at morning and evening feeding periods, resulting in a bi-modal pattern of occupancy during farm operation. The daily pattern of escaped rainbow trout presence at the cage site was similar for both years, with greater occupancy during morning periods that was especially apparent in the final year of production (Fig. 2). In the second year after ceasing operation (post-production; 2008-2009), rainbow trout were rarely detected near the cage site (2008: $0.28 \pm$ $0.03 ; 2009: 0.02 \pm 0.01$ ). Lake trout showed no affinity to the cage site during aquaculture operation (2006: $0.23 \pm 0.03 ; 2007: 0.01 \pm 0.01$ ) or post-production (2008: $0.24 \pm 0.03$; 2009: $0.36 \pm 0.03$ ) (Fig. 2).

The change in presence of escaped rainbow trout at the cage site between production periods was striking (Fig. 3). During aquaculture operation, volumetric space use of the $\mathrm{NCH}$ was much higher for rainbow trout compared to post-production (randomization test, $\mathrm{p}=0.0003$; Table 2 ). Rainbow trout $50 \%$ 3D KUDs showed greater overlap with the cage site during production years (Fig. 3a) compared to the post-production period (Fig. 3b). Furthermore, rainbow trout at the active cage site tended to occupy more of the water column ( 0 to $\sim 7$ m; Fig. $3 \mathrm{c}$ ), compared to a more limited and shallower depth distribution (0 to $\sim 4 \mathrm{~m}$ ) once production had ceased (Fig. 3d). During production, volumetric space use of the $\mathrm{NCH}$ was significantly higher for rainbow trout compared to lake trout ( $p=0.0001$; Table 2$)$. Lake trout did not show a difference in $\mathrm{NCH}$ use over the course of the study ( $p=0.34$; Table 2 ), and $\mathrm{NCH}$ use did not differ significantly between rainbow trout and lake trout during the post-production phase ( $p=0.46$; Table 2$)$.

\section{Habitat use-littoral, pelagic and cage site}

Escaped rainbow trout became more reliant upon the littoral region of the lake once commercial production ceased. The proportion of rainbow trout positions in the littoral zone nearly doubled from the production to the post-production phase (mean $\pm 95 \%$ $\mathrm{CI}_{;} 23.6 \pm 0.7 \%$ to $44.4 \pm 0.9 \%$, respectively, Table 1 ). 


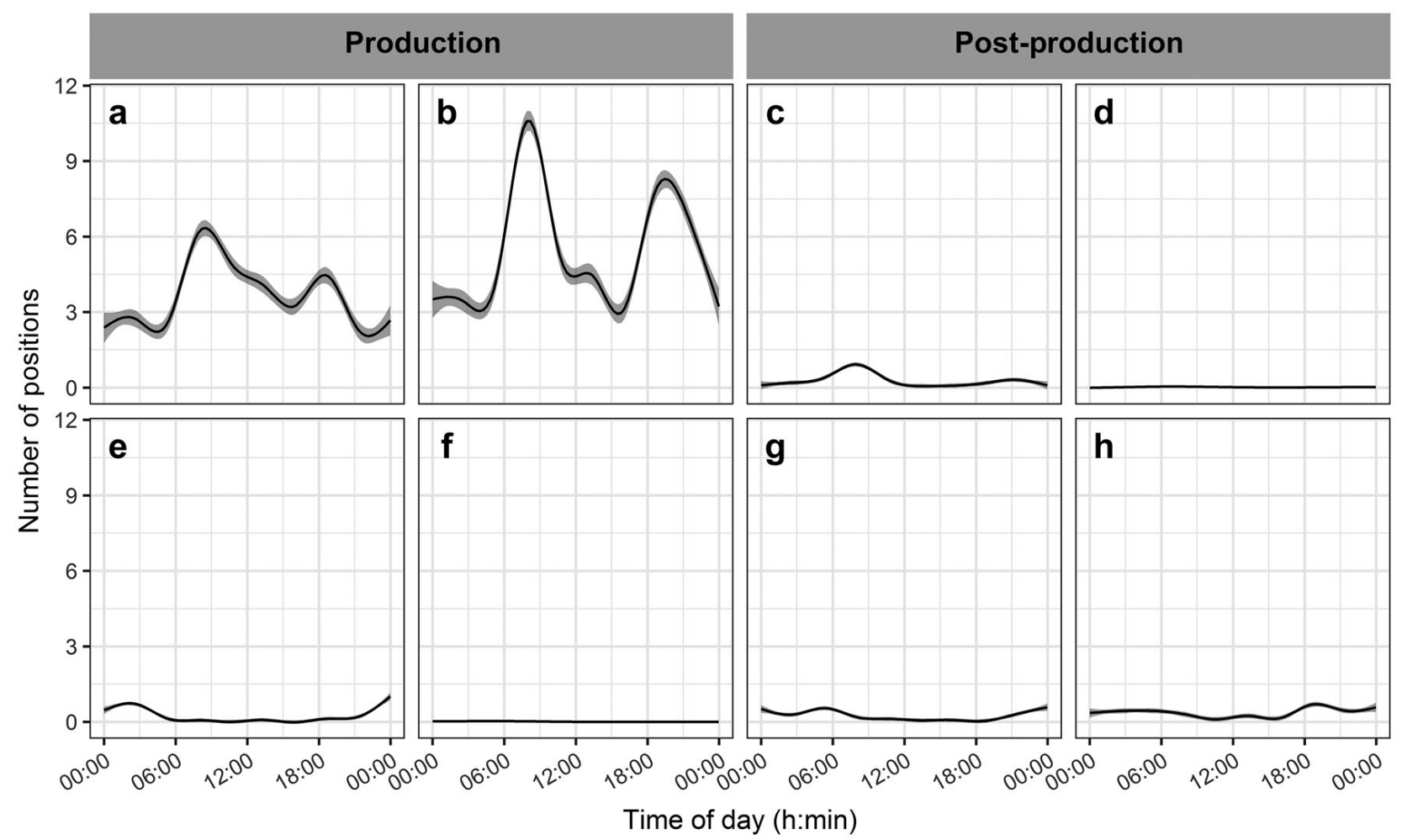

Fig. 2. Positions binned into 1 min intervals of $(\mathrm{a}-\mathrm{d})$ escaped rainbow trout Oncorhynchus mykiss and (e-h) native lake trout Salvelinus namaycush within a $25 \mathrm{~m}$ radius around the cage site during (2006-2007) and after (2008-2009) commercial production. Grey shading indicates $95 \%$ CI

Concomitant with greater use of the littoral region by rainbow trout, there was a significant reduction in presence at the cage site (from $22.6 \pm 0.7 \%$ to $1.8 \pm$ $1.2 \%$, Table 1). Use of the pelagic area of the lake (not including $\mathrm{NCH}$ ) was consistent between production $(53.8 \pm 0.9 \%)$ and post-production $(53.8 \pm 0.5 \%)$ periods (Table 1). Rainbow trout 3D KUDs were not located in the south basin of Lake 375 in the postproduction period (Fig. 3b), although this area was consistently used by some fish during the production period (Fig. 3a).

Lake trout showed a consistent use of all lake habitats that changed little throughout the $4 \mathrm{yr}$ of study, irrespective of the operation of the aquaculture facility. Lake trout primarily occupied the pelagic area $($ production $=81.3 \%$; post-production $=80.1 \%$ ), and to a lesser degree the littoral region (production $=18 \%$; post-production $=18.7 \%$ ), but were rarely detected at the cage site $(0.7 \%$; post-production = $1.2 \%)$. Although lake trout pelagic habitat occupancy was similar throughout the $4 \mathrm{yr}$ of the study, the $95 \%$ CIs showed a statistically significant reduction (Table 1) in use during post-production (79.8$80.5 \%)$ compared to years of aquaculture operation $(80.9-81.7 \%)$.

\section{Habitat use - species overlap}

Rainbow trout were generally found higher in the water column than lake trout (daily means with $95 \%$ CIs), especially during the stratified periods (Fig. 4). Lake trout exhibited seasonal depth changes each year that coincided with changes in surface water temperatures. As temperature increased and hypolimnetic DO became depleted during the summer months (June to September), lake trout habitat was greatly reduced. During the spring and fall, when the lake was not stratified, the 2 species occupied similar depths, especially in the fall during lake trout spawning season (mid-September to mid-October; Fig. 4).

During the production period, lake trout habitat use (50\% core volume: $76914 \mathrm{~m}^{3}$ ) was almost double that of escaped rainbow trout $\left(41974 \mathrm{~m}^{3}\right)$; however, based on overlapping $95 \%$ CIs, this difference was not significant. A similar trend was seen during the post-production phase, where core habitat use estimates for lake trout $\left(38455 \mathrm{~m}^{3}\right)$ were, on average, greater than for rainbow trout $\left(24136 \mathrm{~m}^{3}\right)$, but this was not significant (Table 1). Intra-specific 50\% 3D KUD overlap changed significantly between the production and post-production periods for rainbow trout (CIs, Fig. 5), 


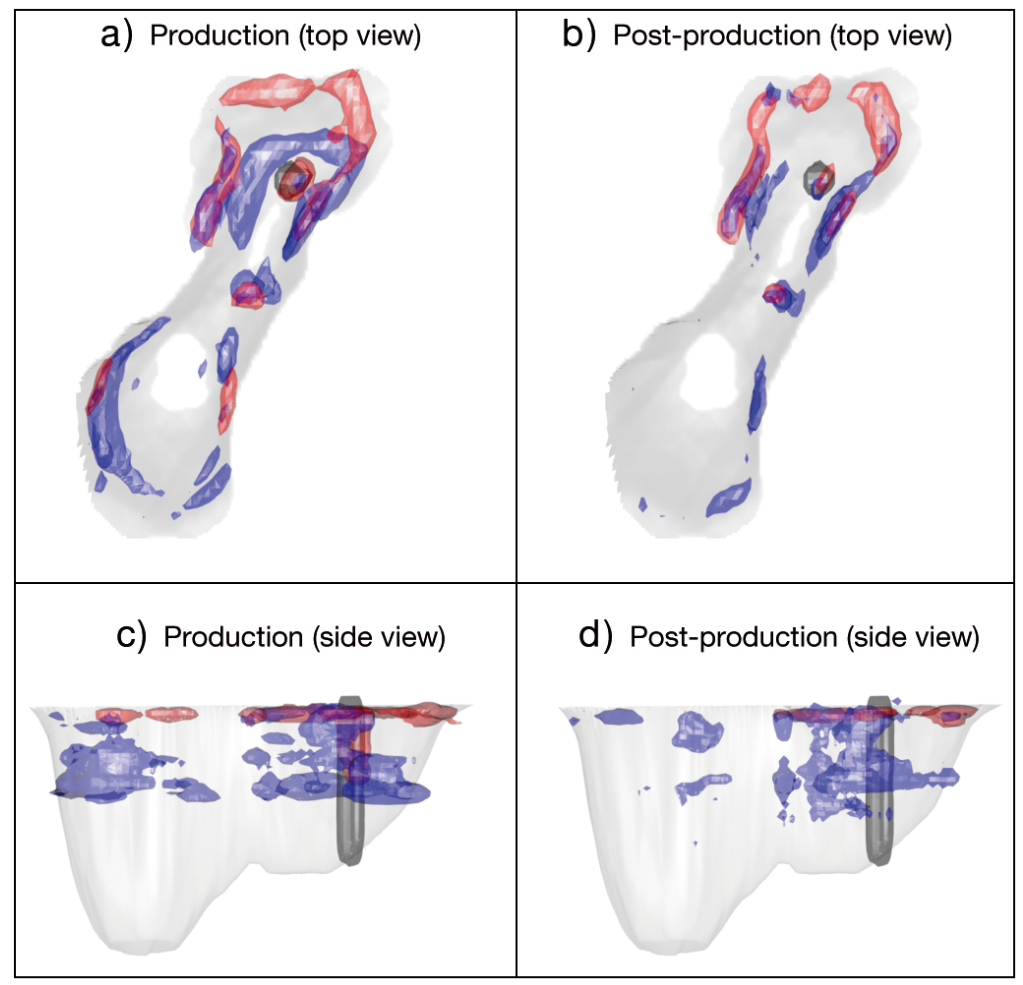

Fig. 3. Core volumetric habitat use (50\% 3D kernel utilization distribution [KUD] - all fish) for escaped rainbow trout Oncorhynchus mykiss (red) and native lake trout Salvelinus namaycush (blue) in Lake 375 (a,c) during commercial production of rainbow trout (Production) and (b,d) after production ceased (Post-production). The near cage habitat ( $\mathrm{NCH}$, see 'Materials and methods') is represented by the black cylinder

but not for lake trout (Fig. 5). During the production period, rainbow trout average intra-specific core habitat overlap was roughly 3 times greater $\left(26355 \mathrm{~m}^{3}\right)$ than during the post-production period $\left(8923 \mathrm{~m}^{3}\right)$. Lake trout showed a slight reduction in $50 \%$ 3D KUD overlap between the production and post-production periods $\left(24047 \mathrm{~m}^{3}\right.$ and $\left.13008 \mathrm{~m}^{3}\right)$; however, the difference was not statistically significant (CIs, Fig. 5). Rainbow trout and lake trout inter-specific overlap was much lower than the intraspecific values and was not different between production $\left(1436 \mathrm{~m}^{3}\right)$ and post-production (1486 $\mathrm{m}^{3}$; Fig. 5) periods.

\section{DISCUSSION}

Opportunities to document the behaviour and habitat use of commercially raised aquaculture fish for extended periods after escape and dispersal from net pens are limited, yet this information is needed if we are to better predict the potential interactions of escapees with the environments, food webs and fish communities that they encounter. This is true for freshwater aquaculture in Canada, where escaped rainbow trout have the potential to interact with lake trout, a native salmonid, but the large lake system (Lake Huron) where much of the commercial production occurs limits detailed examination of inter-specific habitat use. The use of a model farm located in a

Table 2. Comparison of rainbow trout Oncorhynchus mykiss (RT) and lake trout Salvelinus namaycush (LT) volumetric overlap with the cage site (near cage habitat; for details, see Materials and Methods) during years of aquaculture production (2006-2007) and the post-production period (2007-2008). $\mathrm{P}$-values presented are a result of the randomization test; values in bold are significant at $\mathrm{p}<0.05$

\begin{tabular}{|lccccc|}
\hline & \multirow{2}{*}{ Type } & & \multicolumn{3}{c|}{ Overlap with cage $\left(\mathrm{m}^{3}\right)$} \\
\cline { 2 - 5 } Variable 1 & Variable 2 & & Mean & Mean & $\mathrm{p}$ \\
& & variable 1 & variable 2 & \\
\hline RT Production & LT Production & 6977.6 & 660.3 & $\mathbf{0 . 0 0 0 1}$ \\
LT Production & LT Post-production & 660.3 & 369.1 & 0.34 \\
RT Production & RT Post-production & 6977.6 & 407.4 & $\mathbf{0 . 0 0 0 3}$ \\
RT Post-production & LT Post-production & 407.4 & 369.1 & 0.46 \\
& & & & & \\
\hline
\end{tabular}


small lake allowed us to directly examine the behaviour of escaped rainbow trout, and the potential for habitat overlap with lake trout. Escaped rainbow trout were reliant upon the farm site while commercial production was underway, but their distribution shifted towards littoral areas once the farm was no longer in operation. In contrast, lake trout showed no attraction to the farm site, irrespective of the level of production. We anticipated that the small lake used in this study would result in a 'worst-case scenario' for habitat overlap between escaped farmed fish and the native top predator, lake trout, especially after the farm ceased operation. Despite extensive areal overlap, the 2 species showed little actual habitat

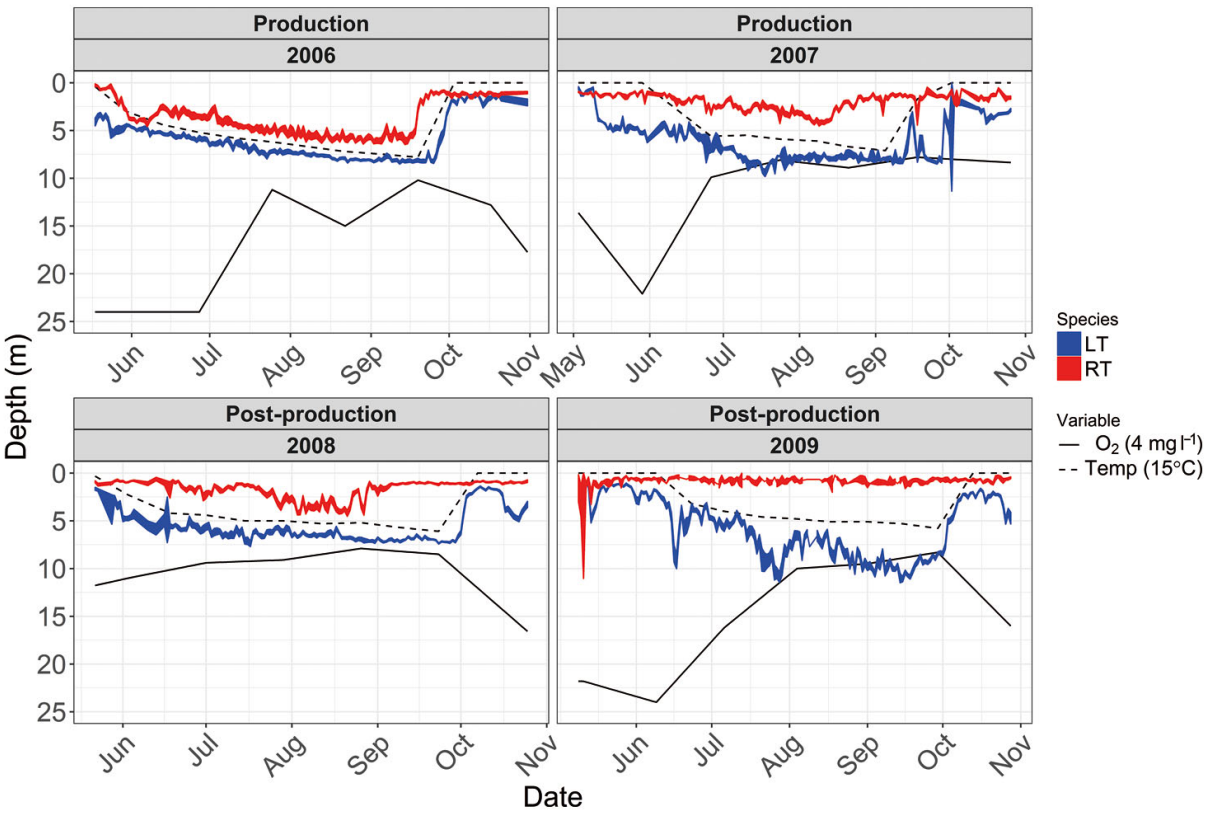

Fig. 4. Mean daily depths $( \pm 95 \% \mathrm{CI}$ ) of escaped rainbow trout Oncorhynchus mykiss (red) and native lake trout Salvelinus namaycush (blue) in Lake 375 during production and post-production of a model aquaculture facility. Optimal oxy-thermal habitat for lake trout is bounded by the upper water temperature of $15^{\circ} \mathrm{C}$ (dashed line), and the lower oxygen threshold of $4 \mathrm{mg} \mathrm{l}^{-1}$ (solid line)

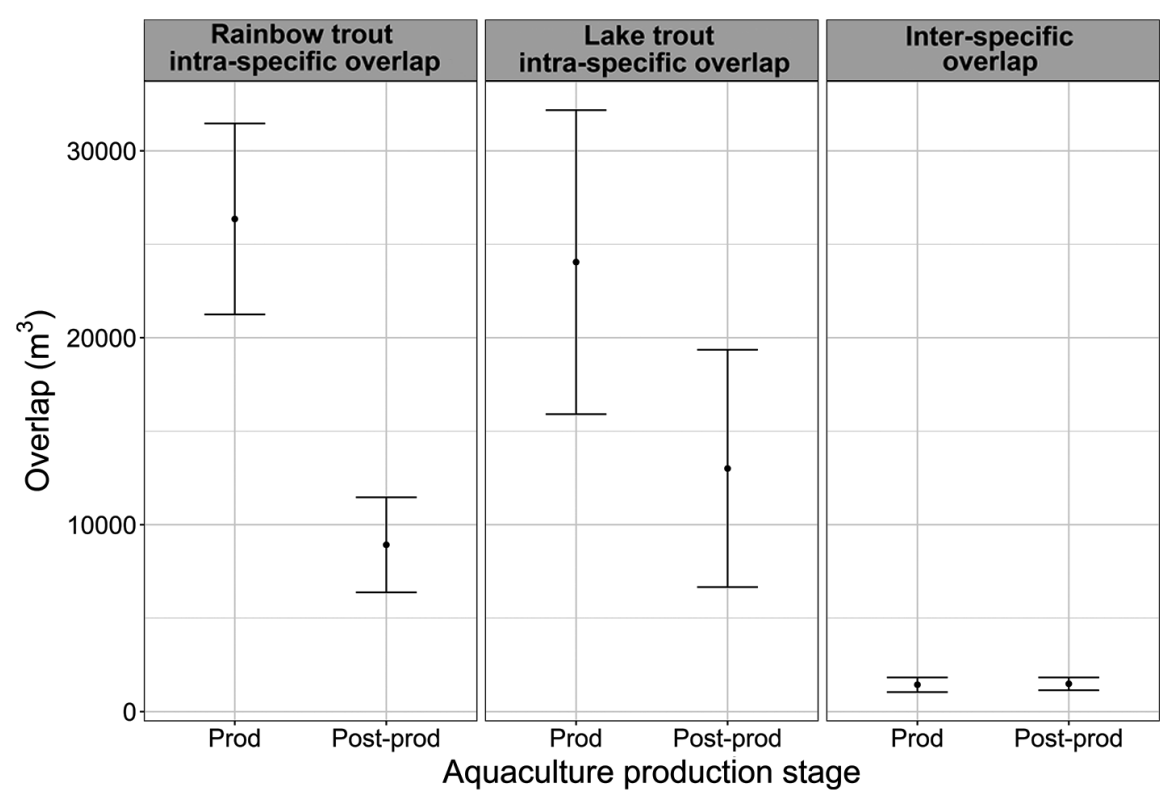

Fig. 5. Inter- and intra-specific 50\% 3D kernel utilization distribution (KUD) overlap for rainbow trout Oncorhynchus mykiss and lake trout Salvelinus namaycush in periods of aquaculture production (Prod) and post-production (Post-prod). Overlap between groups is shown in cubic meters $\left(\mathrm{m}^{3}\right)$ 
overlap because they occupied different depths within the lake. Our findings also highlight that escaped rainbow trout were able to transition from pelagic pen-based behaviours to littoral areas where natural foods were more abundant; therefore, the native fauna in these regions are most likely to be impacted by escapees.

Escaped rainbow trout showed highest fidelity to the cage site during years of continued farm operation in Lake 375, a pattern common to many commercial open-pen operations in marine and fresh waters (Bridger et al. 2001, Blanchfield et al. 2009a, Patterson \& Blanchfield 2013). For example, in a similar study, some rainbow trout escapees in Lake Huron showed strong site fidelity to their site of release, while others made repeated returns to cage sites after extended periods of absence from the farms (Patterson \& Blanchfield 2013). The crepuscular presence of rainbow trout at the cage site in the present study suggests they take advantage of available resources during feeding times, and lends support to the hypothesis that feeding regime has an effect on site fidelity. As the $\mathrm{NCH}$ represented a small amount $(1 \%)$ of the total volume of Lake 375 , we can reasonably conclude that the cage site was an important resource for rainbow trout given that roughly onequarter $(23 \%)$ of their total positions were there during production years compared with only $2 \%$ in the years after production ceased. We observed daily fidelity to the farm site by escaped rainbow trout in the initial years of production in Lake 375, with declining presence at the farm when feeding ceased and fish were removed from the pen on an annual basis (Blanchfield et al. 2009a). The diel pattern in escapee presence at the farm site is likely due to the small lake size, where fish could readily travel to other areas of the lake, yet at most be $<1 \mathrm{~km}$ from the farm. Most studies have not examined escapee presence on such a fine time scale, so whether this pattern might hold true for other systems is unknown.

One clear indication from the daily pattern of movement to the cage site by escapees is that there are food resources available during periods of feeding. We observed little waste feed below the cage during the $5 \mathrm{yr}$ of commercial production, and in support of this observation, we note that rainbow trout $50 \%$ 3D KUDs did not extend to the lake bottom and rainbow trout overlap with the $\mathrm{NCH}$ was highest during this time period. Instead, rainbow trout were generally located in the upper portion of the water column when present at the cage site, and presumably not feeding directly underneath the cage. Based on the daily attraction to the cage site at feeding times by escaped rainbow trout, and their shallow depth distribution, we assume that some feed pellets were shunted out the side of the net pen, where they were consumed. Indeed, the single escaped rainbow trout that we sampled had a diet that consisted of commercial feed pellets, minnows and invertebrates (P. J. Blanchfield unpubl. data). The consumption of waste feed has been noted in 2 marine studies of escaped rainbow trout, although only small fractions $(4 \%$ and $18-21 \%$ ) of farmed recaptured fish contained feed pellets in their stomachs (Abrantes et al. 2011, Skilbrei 2012). In the present study, presumably escaped rainbow trout moved back to the cage site to access waste feed pellets, or else the presence of other food items at the cage that might also be attracted there on a similar daily schedule (Ramos et. al. 2008, Kullman et al. 2009). We regularly captured minnows at the cage site during the study, although our sampling did not allow for determination of their daily movement patterns (P. J. Blanchfield unpubl. data). Because minnow densities are typically greatest in the littoral regions of lakes similar to the study lake (Guzzo et al. 2014), and because stable isotope analyses suggest that aquaculture wastes were not the predominant source of food for minnows (Kullman et al. 2009, Wellman et al. 2017), we presume that rainbow trout attraction to the farm was primarily for the purpose of acquiring waste feed.

Escapees showed a dramatic change in habitat use after operation of the commercial farm ceased. In the post-production period, escaped rainbow trout no longer frequented the farm site; instead, they shifted their distribution towards the near-shore regions of the lake. The increased occupancy of the littoral zone during the post-production period signaled that escapees were quick to adjust to the absence of waste feed, and likely transitioned to foraging in the most productive area of the lake. Unlike studies in small lakes that lack fish, where hatchery rainbow trout occupy offshore areas because of greater food (zooplankton) abundance (Biro et al. 2006), a growing number of studies demonstrate that aquaculture strains of rainbow trout prefer to occupy littoral areas. We observed this pattern during the initial years of this study (Blanchfield et al. 2009a), as well as for farmed rainbow trout released into Lake Huron (Patterson \& Blanchfield 2013), and aquaculture strain juveniles stocked into a small lake (Martens 2013). Escaped rainbow trout in Lake Huron have shown an ability to successfully adapt to natural forage, based on growth and diet metrics (Patterson \& Blanchfield 2013, Johnston \& Wilson 2015), although this is not a universal finding. For example, many of 
the escaped rainbow trout in marine environments were found with empty stomachs, or had stomach contents with little to no nutritional value (e.g. algae, sticks and pieces of wood; Abrantes et al. 2011, Skilbrei 2012). Likewise, there is evidence of weight loss for aquaculture strains of rainbow trout in fresh water, at both juvenile and adult stages (Martens 2013, Patterson \& Blanchfield 2013), which would suggest that not all escapees will be successful in the wild.

While beneficial for understanding escapee behaviour, the use of a model system comes with limitations for extending those findings to commercial aquaculture operations where farmed fish can disperse long distances in the wild. Nonetheless, our findings of rainbow trout behaviour after ceasing commercial production mimic situations such as after dispersal of escapees away from the influence of cage sites, or following cessation of production at sites for fallowing purposes. The presence of a single cage site in the lake did not allow for the movement of escapees among different commercial operations, a pattern that has been seen for farmed rainbow trout in both marine and freshwater ecosystems (Bridger et al. 2001, Patterson \& Blanchfield 2013). The lack of access to alternate cage sites to acquire waste feed may have expedited the switch to natural food for escapees in our study. The rapid reduction in rainbow trout presence at the cage site following cessation of commercial production suggests that escapees would quickly alter their spatial distribution to fallowing practices, and migrate to other operational sites or near-shore areas.

Contrary to other studies where wild fish congregated at commercial aquaculture operations (MacDougall \& Black 1999, Dempster et al. 2002, Fernandez-Jover et al. 2008, Johnston et al. 2010), native lake trout in Lake 375 were not attracted to the cage site. Lake trout were rarely positioned at the cage site ( $1 \%$ of total positions) and showed limited volumetric overlap at the cage site, which did not differ between production and post-production periods. Lake trout exhibited similar use of the area occupied by the $\mathrm{NCH}$, prior to the cage being installed and commencement of farm operations (2002, $0.9 \%$ of total positions; P. J. Blanchfield unpubl. data). Thus, lake trout appeared to occupy the $\mathrm{NCH}$ area of the lake in a similar fashion before, during and after production, with the proportion of positions in accordance with the proportion of the lake volume occupied by the $\mathrm{NCH}(1 \%)$. This is a somewhat surprising finding, given the small size of the lake and the potential for access to additional food resources in an oligotrophic system, where lake trout are typically slow-growing (Mills et al. 2008). Furthermore, lake trout are known to frequent commercial farms in Lake Huron (Johnston et al. 2010), which we predicted they might also do in the present study, especially given the presence of minnows near the cage (P. J. Blanchfield unpubl. data), and declines in Mysis abundance in the latter years of aquaculture production (Paterson et al. 2011). Stable isotope analyses confirmed that lake trout are predators of minnows, but also that they were not highly reliant upon waste feed (Wellman et al. 2017). It should be noted that during the initial years of aquaculture production, lake trout growth rates were greater than they had been in the past, presumably because of a surge in minnow abundance in Lake 375 in response to increased lake productivity (Mills et al. 2008). Thus, lake trout use of the cage site may not have been as profitable as foraging in the littoral regions of the lake.

Fish live in a complex 3D environment where numerous natural factors (light intensity, prey availability and behaviour, etc.) and physiological constraints (thermal and DO) can simultaneously influence behaviour and habitat selection. These factors influence the behaviour of fish in such a way that using traditional 2D KUD methods can be inappropriate to evaluate inter-specific habitat overlap (e.g. Simpfendorfer et al. 2012). Overall we observed minimal habitat overlap (3D) between escaped rainbow trout and native lake trout throughout the study. Habitat use of ectotherms is known to be strongly tied to temperature due to physiological and bioenergetic performance (Rodnick et al. 2004). Northtemperate lakes, especially small lakes like in this study, are subject to periods of stratification, resulting in reduced habitat available to coldwater fishes such as lake trout, which require water temperatures $<15^{\circ} \mathrm{C}$ and DO concentration $>4 \mathrm{mg} \mathrm{l}^{-1}$ (Plumb \& Blanchfield 2009). Rainbow trout have a higher thermal tolerance with an upper lethal temperature $>24^{\circ} \mathrm{C}$ (Bear et al. 2007) and a similar DO limit (4.6 mg $\mathrm{l}^{-1}$ ) for adults (Davis 1975). The species-specific thermal tolerances resulted in significantly deeper depth selection for lake trout $(\sim 7 \mathrm{~m})$ compared to rainbow trout $(\sim 3 \mathrm{~m})$ that increased throughout the stratified period. Even though habitat overlap between escaped rainbow trout and lake trout was minimal, it was most likely amplified in the later years of this study as increasing levels of hypoxic water, a result of increased productivity in the lake from aquaculture operations and lack of complete turnover (Paterson et al. 2011), forced lake trout into shallower depths. The addition of bubblers to Lake 375 in 2009 
helped deliver oxygenated water to the hypolimnion and aided with spring turnover, resulting in a return of lake trout oxy-thermal habitat to normal levels (see Fig. 4; early June 2008 vs. 2009). It is very likely that the decline in oxy-thermal habitat (in 2008) was a major factor leading to the reduction of lake trout 3D KUDs in the post-production period compared with the production period (Table 1). Despite the observed declines in deep-water prey availability in Lake 375 and oxy-thermal habitat in the study lake (Paterson et al. 2011), both of which should have promoted greater inter-specific habitat overlap, we observed limited habitat overlap between lake trout and escaped rainbow trout in the 4 yr of this study.

The potential for habitat overlap between escaped rainbow trout and lake trout is likely greatest when habitat constraints imposed by oxygen and water temperature are lifted, and when lake trout are known to occupy near-shore regions, such as during fall spawning. Indeed, lake trout and farmed rainbow trout showed much more similar depth distributions in early spring and late fall than during the stratified period. How this inter-specific overlap in depth might translate into spatial habitat overlap in Lake Huron, where much of Canada's freshwater aquaculture occurs, is uncertain. In lakes lacking pelagic prey fish, such as our study lake, lake trout rely heavily on near-shore areas for forage in the spring. However, in larger lakes, such as Lake Huron, the presence of various deep-water prey species for lake trout may limit their need to access near-shore areas (Vander Zanden \& Rasmussen 1996), although springtime feeding on littoral prey can be important for growth in lakes with deep-water prey (King et al. 1999). Thus, there is the possibility for indirect impacts to lake trout through reductions in littoral prey by escaped rainbow trout. Fall spawning may also be a period when lake trout and farmed rainbow trout overlap in near-shore regions of Lake Huron, but likely this would not amount to any degree of direct competition, as lake trout are in near-shore regions to spawn. Furthermore, there are offshore spawning reefs in Lake Huron (e.g. Desorcie \& Bowen 2003), where presumably rainbow trout would not frequent. We were not able to assess interspecific habitat overlap of escapees and lake trout during winter. In a lake near our study lake, overwinter telemetry data showed that lake trout had small home ranges that were positioned in the central portion of the lake, where they occupied the upper water column (Blanchfield et al. 2009c). Although spatial data for the winter months were not available, the depths of lake trout and rainbow trout (from VR2 receivers) show limited pelagic overlap during the winter months, suggesting that even if there were spatial overlap, these species would likely have limited interaction because of depth segregation.

\section{CONCLUSIONS AND FUTURE STUDIES}

We have demonstrated that escaped rainbow trout rapidly changed habitat use in response to food availability during and after periods of commercial aquaculture production. Interactions between escapees and native lake trout appeared to be limited, and did not change irrespective of production cycle, primarily due to the lack of attraction by lake trout to cage operations. Escaped rainbow trout showed an attraction to near-shore regions of the lake once commercial production ceased, and this is an area where further study is needed if we are to better quantify the extent to which escapees may directly or indirectly alter trophic dynamics in nearshore regions of Lake Huron.

Acknowledgements. We appreciate the field support of all ELA staff and students who worked on the aquaculture project. Funding for this study was provided by Fisheries and Oceans Canada and the Experimental Lakes Graduate Fellowship. We would like to thank the anonymous reviewers for their helpful comments and suggestions.

\section{LITERATURE CITED}

Abrantes KG, Lyle JM, Nichols PD, Semmens JM (2011) Do exotic salmonids feed on native fauna after escaping from aquaculture cages in Tasmania, Australia? Can J Fish Aquat Sci 68:1539-1551

Azevedo P, Podemski C, Hesslein R, Kasian S, Findlay D, Bureau D (2011) Estimation of waste outputs by a rainbow trout cage farm using a nutritional approach and monitoring of lake water quality. Aquaculture 311:175-186

Bear E, McMahon T, Zale A (2007) Comparative thermal requirements of westslope cutthroat trout and rainbow trout: implications for species interactions and development of thermal protection standards. Trans Am Fish Soc 136:1113-1121

Biro PA, Abrahams MV, Post JR, Parkinson EA (2006) Behavioural trade offs between growth and mortality explain evolution of submaximal growth rates. J Anim Ecol 75:1165-1171

* Blanchfield PJ, Flavelle LS, Hodge TH, Orihel DM (2005) The response of lake trout to manual tracking. Trans Am Fish Soc 134:346-355

Blanchfield PJ, Tate L, Podemski C (2009a) Survival and behaviour of rainbow trout (Oncorhynchus mykiss) released from an experimental aquaculture operation. Can J Fish Aquat Sci 66:1976-1988

Blanchfield PJ, Paterson MJ, Shearer JA, Schindler DW 
(2009b) Johnson and Vallentyne's legacy: 40 years of aquatic research at the Experimental Lakes Area. Can J Fish Aquat Sci 66:1831-1836

Blanchfield PJ, Tate LS, Plumb JM, Acolas MLA, Beaty KG (2009c) Seasonal habitat selection by lake trout (Salvelinus namaycush) in a Canadian shield lake: constraints imposed by winter conditions. Aquat Ecol 43:777-787

Bridger CJ, Booth RK, McKinley RS, Scruton DA (2001) Site fidelity and dispersal patterns of domestic triploid steelhead trout (Oncorhynchus mykiss Walbaum) released to the wild. ICES J Mar Sci 58:510-516

Bristow CE, Morin A, Hesslein RH, Podemski CL (2008) Phosphorus budget and productivity of an experimental lake during the initial three years of cage aquaculture. Can J Fish Aquat Sci 65:2485-2495

Charles C, Gillis DM, Hrenchuk LE, Blanchfield PJ (2016) A method of spatial correction for acoustic positioning biotelemetry. Anim Biotelem 4:5

Chittenden CM, Rikardsen AH, Skilbrei OT, Davidsen JG, Halttunen E, Skardhamar J, McKinley RS (2011) An effective method for the recapture of escaped farmed salmon. Aquacult Environ Interact 1:215-224

Consuegra S, Phillips N, Gajardo G, de Leaniz CG (2011) Winning the invasion roulette: escapes from fish farms increase admixture and facilitate establishment of nonnative rainbow trout. Evol Appl 4:660-671

* Davis JC (1975) Minimal dissolved oxygen requirements of aquatic life with emphasis on Canadian species: a review. J Fish Res Board Can 32:2295-2332

* Dempster T, Sanchez-Jerez P, Bayle-Sempere JT, GiménezCasalduero F, Valle C (2002) Attraction of wild fish to sea-cage fish farms in the south-western Mediterranean Sea: spatial and short-term temporal variability. Mar Ecol Prog Ser 242:237-252

* Desorcie TJ, Bowen CA (2003) Evidence of offshore lake trout reproduction in Lake Huron. N Am J Fish Manag 23:1253-1256

DFO (Department of Fisheries and Oceans) (2015) Aquaculture: production quantities and values. www.dfompo.gc.ca/stats/aqua/aqua-prod-eng.htm (accessed 15 Dec 2015)

* Dunlop ES, Milne SW, Ridgway MS (2010) Temporal trends in the numbers and characteristics of Lake Huron fish schools between 2000 and 2004. J Gt Lakes Res 36:74-85

Duong T (2007) ks: Kernel density estimation and kernel discriminant analysis for multivariate data. J Stat Softw 21:1-16

Duong T (2016) ks: Kernel smoothing. R package version 1.10.4. http://CRAN.R-project.org/package=ks

Ellis T, Turnbull JF, Knowles TG, Lines JA, Auchterlonie NA (2016) Trends during development of Scottish salmon farming: an example of sustainable intensification? Aquaculture 458:82-99

FAO (Food and Agriculture Organization of the United Nations) (2016) The state of world fisheries and aquaculture 2016. FAO, Rome

Fernandez-Jover D, Sanchez-Jerez P, Bayle-Sempere J, Valle C, Dempster T (2008) Seasonal patterns and diets of wild fish assemblages associated with Mediterranean coastal fish farms. ICES J Mar Sci 65:1153-1160

* Findlay DL, Podemski CL, Kasian SEM (2009) Aquaculture impacts on the algal and bacterial communities in a small boreal forest lake. Can J Fish Aquat Sci 66:1936-1948

Gross MR (1998) One species with two biologies: Atlantic salmon (Salmo salar) in the wild and in aquaculture. Can
J Fish Aquat Sci 55:131-144

KGuzzo MM, Rennie MD, Blanchfield PJ (2014) Evaluating the relationship between mean catch per unit effort and abundance for littoral cyprinids in small boreal shield lakes. Fish Res 150:100-108

Guzzo MM, Blanchfield PJ, Chapelsky AJ, Cott PA (2016) Resource partitioning among top-level piscivores in a sub-Arctic lake during thermal stratification. J Gt Lakes Res 42:276-285

* Johnston TA, Wilson CC (2015) Comparative ecologies of domestic and naturalised rainbow trout in northern Lake Huron. Ecol Freshw Fish 24:338-354

Johnston TA, Keir M, Power M (2010) Response of native and naturalized fish to salmonid cage culture farms in Northern Lake Huron. Canada. Trans Am Fish Soc 139: $660-670$

KKing JR, Shuter BJ, Zimmerman AP (1999) Empirical links between thermal habitat, fish growth, and climate change. Trans Am Fish Soc 128:656-665

Kullman MA, Kidd KA, Podemski CL, Paterson MJ, Blanchfield PJ (2009) Assimilation of freshwater salmonid aquaculture waste by native aquatic biota. Can J Fish Aquat Sci 66:1965-1975

*MacDougall N, Black KD (1999) Determining sediment properties around a marine cage farm using acoustic ground discrimination: RoxAnn ${ }^{\mathrm{TM}}$. Aquacult Res 30: 451-458

Manly B (1997) Randomization, bootstrapping and Monte Carlo methods in biology. Chapman \& Hall, London

Martens MT (2013) The comparative growth and survival of a naturalized and aquaculture strain of rainbow trout (Oncorhynchus mykiss) in laboratory and wholeecosystem experiments. MSc thesis, University of Manitoba, Winnipeg

*McGhie TK, Crawford CM, Mitchell IM, O'Brien D (2000) The degradation of fish-cage waste in sediments during fallowing. Aquaculture 187:351-366

Mills KH, Chalanchuk SM, Blanchfield PJ, Podemski CL, Allan DJ (2008) Enhanced growth and condition of lake trout in a small Ontario lake during cage aquaculture of rainbow trout. Can Tech Rep Fish Aquat Sci 2778:200-202

Naylor R, Hindar K, Fleming I, Goldburg R and others (2005) Fugitive salmon, assessing the risks of escaped fish from net-pen aquaculture. Bioscience 55:427-437

O'Connor DV, Rottiers DV, Berlin WH (1981) Food consumption, growth rate, conversion efficiency, and proximate composition of yearling lake trout. Admin Rep 81-5. Great Lakes Fish Lab, Ann Arbor, MI

* Pascual MA, Lancelotti JL, Ernst B, Ciancio JE, Aedo E, García-Asorey M (2009) Scale, connectivity, and incentives in the introduction and management of non native species: the case of exotic salmonids in Patagonia. Front Ecol Environ 7:533-540

* Paterson MJ, Podemski CL, Findlay WJ, Findlay DL, Salki AG (2010) The response of zooplankton in a whole-lake experiment on the effects of a cage aquaculture operation for rainbow trout (Oncorhynchus mykiss). Can J Fish Aquat Sci 67:1852-1861

* Paterson M, Podemski C, Wesson L, Dupuis A (2011) The effects of an experimental freshwater cage aquaculture operation on Mysis diluviana. J Plankton Res 33:25-36

* Patterson K, Blanchfield PJ (2013) Oncorhynchus mykiss escaped from commercial freshwater aquaculture pens in Lake Huron, Canada. Aquacult Environ Interact 4: 53-65 
Plumb J, Blanchfield PJ (2009) Performance of temperature and dissolved oxygen criteria to predict habitat use by lake trout (Salvelinus namaycush). Can J Fish Aquat Sci 66:2011-2023

Podemski CL, Blanchfield PJ (2006) Overview of the environmental impacts of Canadian freshwater aquaculture. A scientific review of the potential environmental effects of aquaculture in aquatic ecosystems. Volume V. Can Tech Rep Fish Aquat Sci 2450:30-79

R Core Team (2016) R: a language and environment for statistical computing. R Foundation for Statistical Computing, Vienna. www.R-project.org/

Ramos IP, Vidotto-Magnoni AP, Carvalho ED (2008) Influence of cage fish farming on the diet of dominant fish species of a Brazilian reservoir (Tietê River, High Paraná River Basin). Acta Limnol Bras 20:245-252

Reid GK, McMillan I, Moccia RD (2006) Near-field loading dynamics of phosphorus and short-term water quality correlations at a rainbow trout cage farm in Lake Huron. J Environ Monit 8:947-954

Riley SC, Roseman EF, Nichols SJ, O'Brien TP, Kiley CS, Schaeffer JS (2008) Deepwater demersal fish community collapse in Lake Huron. Trans Am Fish Soc 137: 1879-1890

Rodnick KJ, Gamperl AK, Lizars KR, Bennett MT, Rausch RN, Keeley ER (2004) Thermal tolerance and metabolic physiology among redband trout populations in southeastern Oregon. J Fish Biol 64:310-335

Rooney R, Podemski C (2009) Effects of an experimental rainbow trout (Oncorhynchus mykiss) farm on invertebrate community composition. Can J Fish Aquat Sci 66: 1949-1964

Sellers TJ, Parker BR, Schindler DW, Tonn WM (1998)

Editorial responsibility: Pablo Sánchez Jerez, Alicante, Spain
Pelagic distribution of lake trout (Salvelinus namaycush) in small Canadian Shield lakes with respect to temperature, dissolved oxygen, and light. Can J Fish Aquat Sci 55:170-179

Simpfendorfer CA, Olsen EM, Heupel MR, Moland E (2012) Three-dimensional kernel utilization distributions improve estimates of space use in aquatic animals. Can J Fish Aquat Sci 69:565-572

* Skilbrei OT (2012) The importance of escaped farmed rainbow trout (Oncorhynchus mykiss) as a vector for the salmon louse (Lepeophtheirus salmonis) depends on the hydrological conditions in the fjord. Hydrobiologia 686: 287-297

Soto D, Arismendi I, Gonzalez J, Sanzana J, Jara F, Guzman E, Lara A (2006) Southern Chile, trout and salmon country: invasion patterns and threats for native species. Rev Chil Hist Nat 79:97-117

Vander Zanden M, Rasmussen J (1996) A trophic position model of pelagic food webs: impact on contaminant bioaccumulation in lake trout. Ecol Monogr 66:451-477

* Wellman S, Kidd KA, Podemski CL, Blanchfield PJ, Paterson MJ (2017) Incorporation of wastes by native species during and after an experimental aquaculture operation. Freshw Sci 36:387-401

*Worton BJ (1987) A review of models of home range for animal movement. Ecol Model 38:277-298

* Yan ND (2005) Research needs for the management of water quality issues, particularly phosphorus and oxygen concentrations, related to salmonid cage aquaculture in Canadian freshwaters. Environ Rev 13:1-19

Z Zhulay I, Reiss K, Reiss H (2015) Effects of aquaculture fallowing on the recovery of macrofauna communities. Mar Pollut Bull 97:381-390

Submitted: February 27, 2017; Accepted: September 4, 2017 Proofs received from author(s): October 13, 2017 